\title{
Report on a Collection of Lutzomyia Sand Flies (Diptera: Psychodidae) from the Middle Solimões (Amazonas, Brazil)
}

\author{
Toby Vincent Barrett*, Rui Alves de Freitas, Maria Ivonei Carvalho \\ Albuquerque*, José Camilo Hurtado Guerrero*
}

\author{
Coordenação de Pesquisas em Ciências da Saúde, Instituto Nacional de Pesquisas da Amazônia - INPA, \\ Caixa Postal 478, 69011-970 Manaus, AM, Brasil
}

Fifty-two species of Lutzomyia sand flies were identified in contemporaneous samples totalling only 1875 individuals, collected at the same site in tall primary terra-firme rainforest, near the south bank of the Solimões River. The most abundant species belonged to the subgenera Trichophoromyia and Nyssomyia. The subgenera Psathyromyia, Nyssomyia and Psychodopygus represented the greatest number of species. A new, aberrant species of the subgenus Psathyromyia (L. cultellata) and the female of $\mathrm{Lu}$. souzacastroi are described. The Phlebotominae are proposed as a suitable indicator group for biogeographic and diversity studies.

Key words: Diptera - Psychodidae - new species - diversity - Logseries model - sample size

Surveys of phlebotomines carried out during the course of studies on leishmaniasis generate information which is potentially relevant not only to medical entomology, but also to research on biogeography, models of areas of endemism, processes of speciation, and identification of priority areas for biological conservation. The purpose of the present report is to describe a sample of Phlebotominae with exceptionally high species diversity, from the central Amazon basin, in a form suitable for comparison with other samples; and to describe the female of Lutzomyia souzacastroi and a new species encountered at the collection site. The sampling programme was originally designed to evaluate the effect of insecticidal fogging on phlebotomines in forest areas where geophysical survey teams are exposed to leishmaniasis; the results of that trial have been summarized elsewhere (Barrett et al. 1993). The advantages of Phlebotominae as an indicator group and the economic presentation of data, without loss of essential information, are briefly discussed.

\section{MATERIALS AND METHODS}

Study area - Tall primary terra-firme lowland rainforest at $03^{\circ} 40^{\prime} 42^{\prime \prime} \mathrm{S}, 6^{\circ} 21^{\prime} 30^{\prime \prime} \mathrm{W}$, approximately $11 \mathrm{~km}$ south of the Solimões River at Caiambé, near clearing 7 seismic survey line 99ES238, between Igarapé Caiambé and Igarapé Jutica, Tefé municipality, State of Amazonas, Brazil.

Work supported by the Research Agreement INPA/ PETROBRÁS

*CNPq grant holders

Received 19 April 1995

Accepted 16 August 1995
Sampling - Five pairs of light-traps were set at distances of 0-50m from an encampment with four persons, and another five pairs at a distance of $2000 \mathrm{~m}$. Each pair consisted of one trap powered by four $1.5 \mathrm{~V}$ batteries and one trap powered by a rechargeable $6 \mathrm{~V}$ motorcycle battery, $5 \mathrm{~m}$ apart. All traps were set at $1 \mathrm{~m}$ above the forest floor and operated with fresh batteries each night between 1/9/91 and 11/9/91 except for the rechargeable traps on one night, giving a total of 210 trapnights. Human landing catches were done by one collector between 1900 and $2000 \mathrm{hr}$ on the first eight nights, and during the day phlebotomines were sought on tree bases and other potential resting sites.

Data analysis - Log relative abundance was determined with a pocket calculator (Casio fx3600P) and plotted on ordinary graph paper (Fig. $5)$. The Fisher-Williams diversity statistic $\alpha$ was calculated by trial and error from known numbers of species $(\mathrm{S})$ and numbers of individuals $(\mathrm{N})$ in the formula $S=\alpha \ln (1+\mathrm{N} / \alpha)$. Taylor et al. (1976) give the variance of this estimate as $\alpha /-\log (1-\mathrm{x})$, where $\mathrm{x}$ is a sampling parameter, but because (1$\mathrm{x})$ may be negative, and the expected number of species in a sample is given by these authors as $\alpha \log (1-x)$, we estimated the variance of $\alpha$ as $\alpha^{2} / S$. Maximum and minimum values of $S$ expected for $\alpha \pm 1$ standard deviation were then calculated for observed values of $\alpha$ as $\mathrm{N}$ accumulated in the collectors' curve (Fig. 6).

Females of species difficult to separate in this sex were allocated in proportion to the number of males collected. Note, therefore, that no males of $L$. dendrophyla or L. scaffi were collected in lighttraps, and Shannoni-group females were allocated to these species in Fig. 5 on the basis of the tree- 
base collection.

Taxonomy - Classification of previously known species follows Young and Duncan (1994). Measurements are mean values in millimeters with range in parentheses, and are for specimens cleared in $\mathrm{NaOH}$ and phenol.

\section{TAXONOMIC DESCRIPTIONS}

Lutzomyia cultellata Freitas \& Albuquerque, n. sp. (Fig. 1)

Male (only specimens known): general colour light brown, pleura paler than scutum and coxae. Length of insect 2.30 (2.28-2.32). Wings 1.87 (1.81-1.99) long, 0.53 (0.47-0.62) wide. Head height from vertex to tip of clypeus $0.350(0.312$ 0.370 ), width 0.364 (0.351-0.377). Eyes separated by $0.085(0.071-0.097)$ or 4.5 facet diameters. Interocular suture incomplete. Cibarium unarmed, cibarial arch complete but diffuse medially, pigment patch ill-defined. Pharynx unarmed, finely striated postero-medially. Flagellomere I 0.234 (0.214-0.247) long, combined length of II + III $0.221(0.218-0.227)$. Ascoids present on all flagellomeres except last three, bigeniculate with pointed posterior spur. Length of palpomeres: I, 0.039; II, 0.082 (0.078-0.091); III, 0.120 (0.110$0.130)$; IV, 0.062 (0.052-0.071); V, 0.121 (0.1100.130 ); III subequal to V. Pleura with 17 (11-26) upper and 5 (2-10) lower episternal setae. Length of wing vein sections: alpha 0.42 (0.36-0.53), beta 0.23 , gamma 0.23 (0.21-0.23), delta 0.09 (0.060.14). Legs unarmed, lengths of femora, tibiae and basitarsi: foreleg, 0.68, 0.71-0.79, 0.45; midleg, 0.70-0.80, 0.90-1.06, 0.57; hindleg, 0.83, 1.17, 0.62 . Style $0.141(0.136-0.143)$ long with four major spines of which two are apical, one is inserted in the median third of the segment and one in the distal third, closest to the apical pair; no subterminal seta. Coxite 0.264 (0.253-0.273) long, with a basal tuft of 15-18 hairlike setae inserted individually on closely grouped, pigmented tuberculosities. Paramere simple, narrowing abruptly in its distal half along the ventral margin; distal half with fine setae as shown. Lateral lobe simple, subcylindrical, 0.245 (0.240-0.253) long. Aedeagus conical, elongate, lightly pigmented. Genital pump 0.063 (0.060-0.066) long; filaments $0.295(0.283-0.302)$ long or slightly less than $5 \mathrm{x}$ length of pump, tips simple. Cerci normal.

Material examined: three specimens from Brazil, State of Amazonas, 03 40'42" S, 64 21'30" W, light-traps, TV Barrett and FL Santos. Holotype, 8/9/91, to be deposited in the Entomology Collection at Instituto Nacional de Pesquisas da Amazônia - INPA, Manaus; two paratypes, 6/9/
91. The specific name is a Latin adjective referring to the shape of the paramere, which resembles a small kitchen cleaver in outline.

Remarks: the form of the ascoids, the palpal formula, and the simple paramere of the males are characteristic of the subgenus Psathyromyia. Lutzomyia cultellata is readily distinguished from the other species of this group by the presence of an apical pair of major setae on the style and a well-developed basal tuft on the coxite. The ungrouped species, L. ignacioi Young has a diffuse coxite tuft, but in that species the posterior spurs of the ascoids are vestigial, the arrangement of the major setae of the style is quite different and the genital filaments are much shorter than in L. cultellata. Group characters of the subgenus Psathyromyia include the absence of a basal tuft on the coxite (Theodor 1965, Young \& Duncan 1994) and will require re-definition if our classification of $L$. cultellata is accepted.

\section{Lutzomyia souzacastroi}

(Damasceno and Causey, 1944)

L. souzacastroi: Young and Duncan, 1994, Fig. 146 (holotype)

(Figs 2, 3)

Male: specimens in this collection as described for type material, with the following additional observations and consistent minor differences. General colour light brown, scutum, pronotum and apex of scutellum contrasting strongly with pale pleura and coxae. Pleura with 10(5-14) upper and 3(2-4) lower episternal setae. Genital pump 0.19 (0.18-0.22) long, filaments 0.40 (0.39-0.45) long, ratio of pump to filaments 1.0:2.1 (1.0:1.9 1.0:2.5); tips of filaments spoon-like, more strongly expanded than shown for holotype. Ventral margin of paramere as shown for holotype (external aspect) or transition between wide basal and narrow apical portions of segment more gradual and obtuse (internal aspect). Aedeagus truncated at apex.

Female: colouration as in male. Length 1.91 (1.87-1.95). Wings 1.91 (1.87-1.95) long, 0.55 (0.53-0.57) wide. Head height from vertex to tip of clypeus 0.329 (0.321-0.337), width 0.350 (0.344-0.357). Eyes separated by $0.072(0.068$ 0.078 ) or 5.6 facet diameters. Interocular suture incomplete. Cibarium with 4 horizontal teeth, and 41 (38-44) vertical teeth irregularly arranged in 4 horizontal rows. Cibarial arch complete, pigment patch poorly defined. Pharynx 0.158 long, posterior third armed with about 20 transverse combs of minute teeth. Flagellomere I 0.250 (0.247$0.253)$ long, combined lengths of II+III 0.226 (0.207-0.253). Ascoids visible on flagellomeres I- 

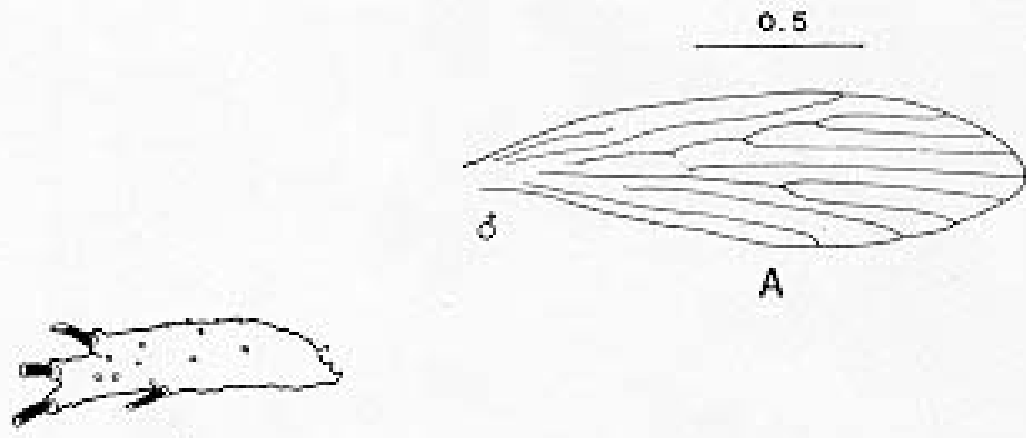

B

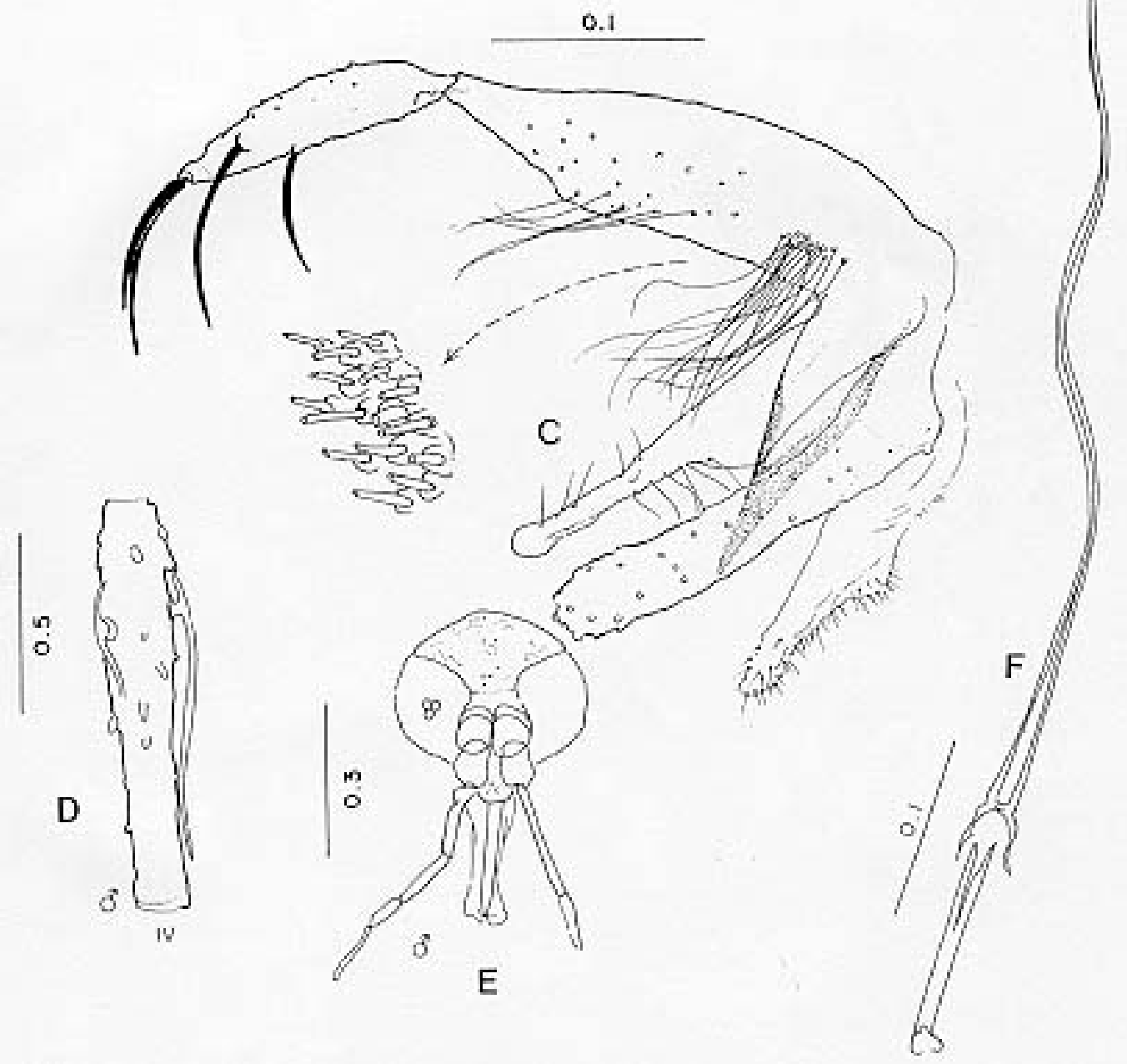

Fig. 1: Lutzomyia cultellata Freitas \& Albuquerque, n.sp., male. A: wing, B: insertion of spines on style. C: terminalia. D: second flagellomere. E: head. F: genital pump and filaments.

IX, pointed posterior spur reaching level of base of flagellomere except on flagellomere I. Labrum $0.234(0.227-0.240)$ long. Length of palpomeres: I, 0.045; II, 0.110 (0.104-0.117); III, 0.115 (0.1140.117); IV, 0.047 (0.045-0.049); V, 0.149 (0.136$0.162)$. Length of wing vein sections: alpha 0.48 (0.46-0.51), beta 0.20, gamma 0.16(0.15-0.16), delta 0.17 (0.15-0.18); gamma longer or shorter than delta. Pleura with 10 upper and 2 lower (11 upper and 4 lower) episternal setae. Legs unarmed, lengths of femora, tibiae and basitarsi: foreleg 0.84 , 1.28, 0.83; midleg 0.70, 1.37, 0.88; hindleg 0.76, $1.57,0.95$. Spermathecae smooth-walled, elongate; body 0.06 long; head 0.013 long and half as wide, 

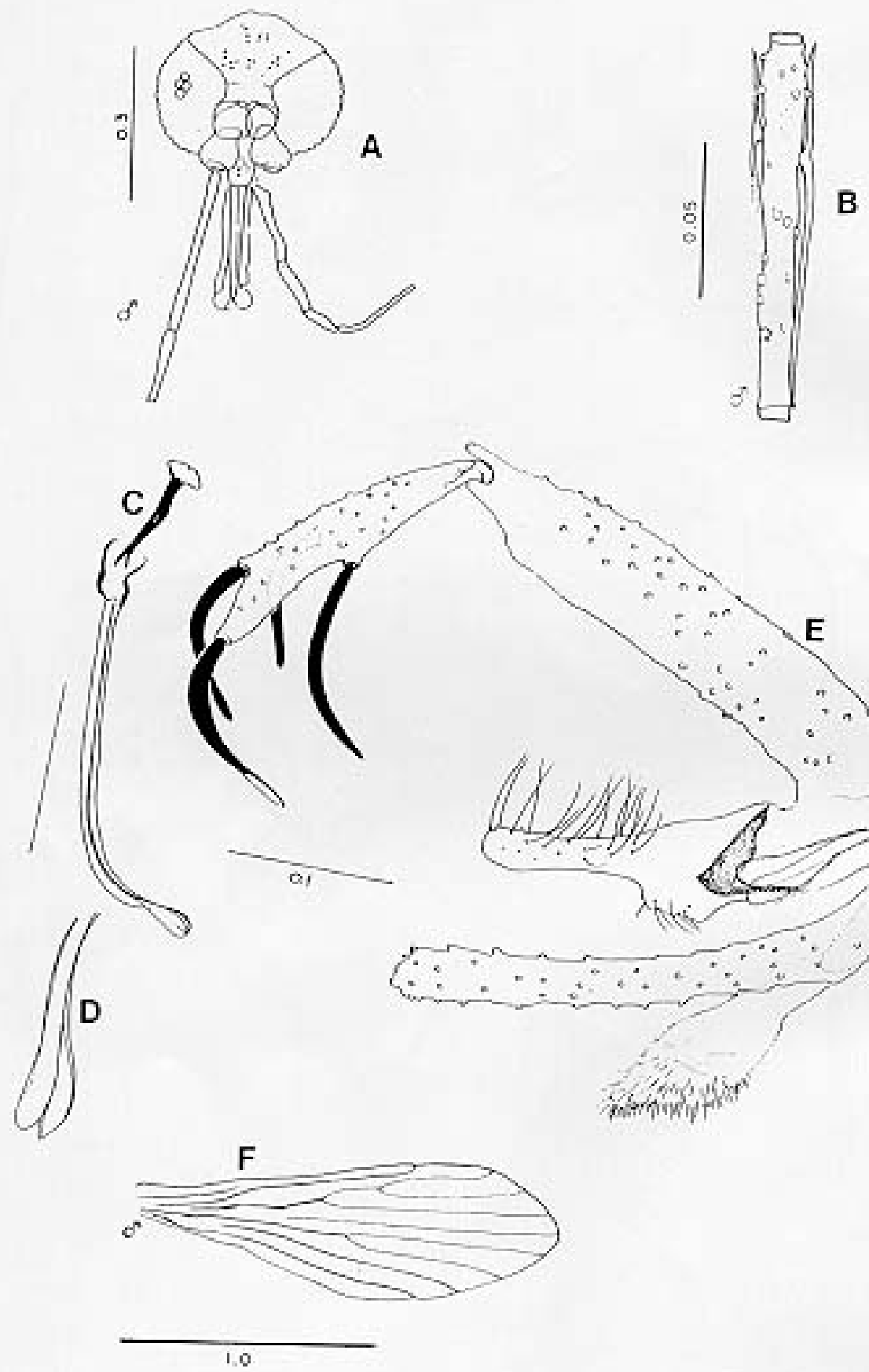

Fig. 2: Lutzomyia souzacastroi from Caiambé, male. A: head. B: second flagellomere. C: genital pump and filaments. D: tips of genital filaments. E: terminalia. F: wing.

salient; common duct longer than individual ducts, the latter subequal to body of spermatheca. Stem of genital fork narrow. Cerci normal.

Material examined: Brazil, State of Amazonas, $03^{\circ} 40^{\prime} 42^{\prime \prime} \mathrm{S}, 64^{\circ} 21^{\prime} 30^{\prime \prime} \mathrm{W}$, tree trunks, TV Barrett 6/9/91. 20 males, 2 females. Five male and one female voucher specimens to be deposited in the INPA Entomology Collections - Manaus.

Remarks: the original description of $L$. souzacastroi was based on two male specimens from Amazonian caatinga vegetation on the Upper Solimões River. In our material, 64 of the characters studied for males were compatible with the original description, and we are provisionally treat- 

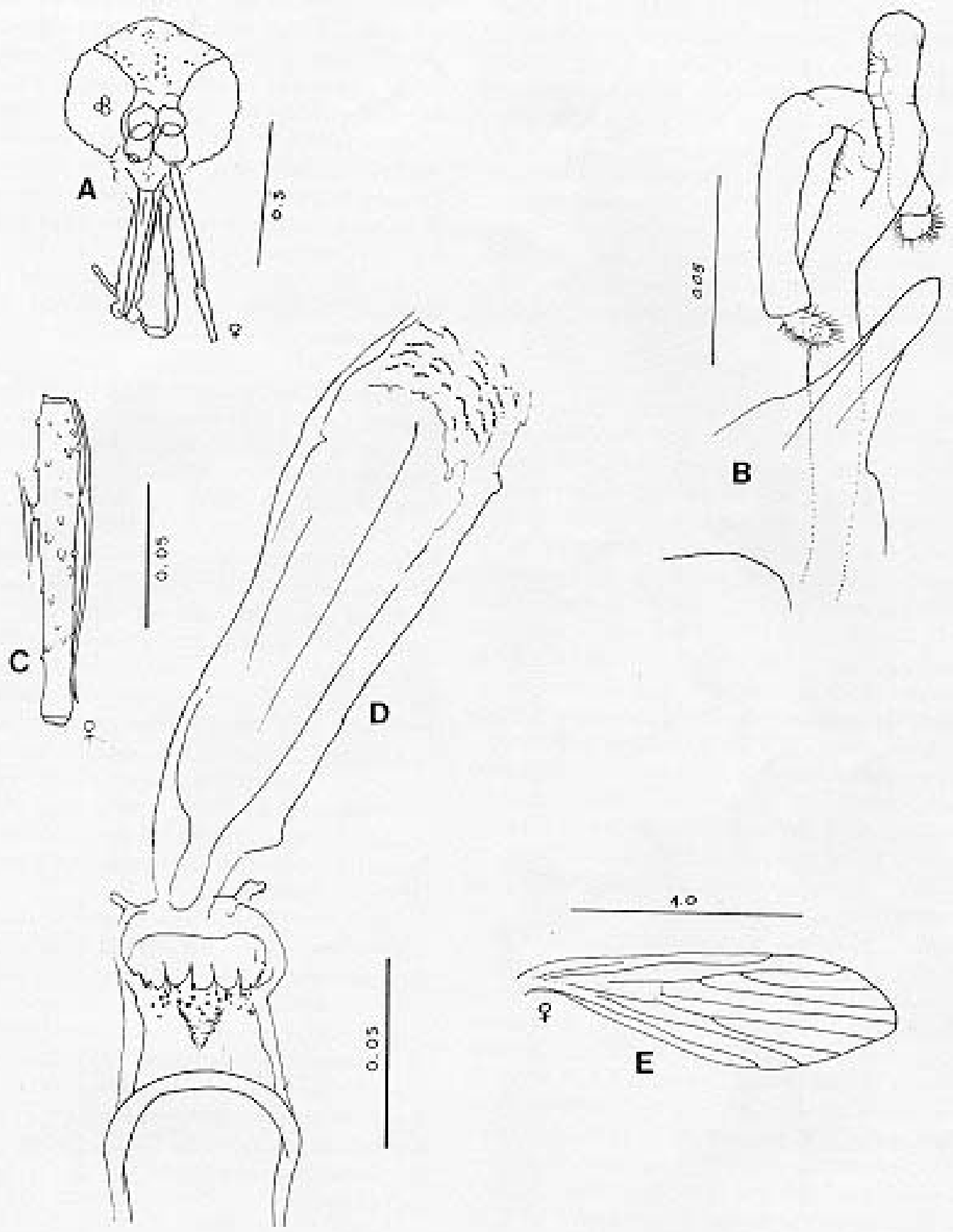

Fig. 3: Lutzomyia souzacastroi from Caiambé, female. A: head. B: spermathecae and genital fork. C: second flagellomere. D: pharynx and cibarium. E: wing.

ing the differences in the relative lengths of the genital pump and filaments $(1:>3$ in the type specimens) the shape of the aedegi (triangular in the original description) and tips of the genital filaments as variation within a single morphospecies.

Females of $L$. souzacastroi were collected together with males on the same trunks. They can be distinguished from other known Psathyromyia females with pale pleura, four horizontal cibarial teeth and elongated, smooth-walled spermathecae (L. shannoni, L. abonnenci and L. pestanai) by the relatively large spermathecal head and wide individual ducts. Of the species whose females are unknown, $L$. socculus has been reported only from Central America, L. cuzquena is a larger species with pigmented pleura, and $L$. cultellata has darker 
pleura and ascoids with shorter posterior spurs. The peculiar serrated ridges of the pharyngeal armature in $L$. souzacastroi have not been reported in any other females of the subgenus, although Dias et al. (1991) have described similar structures in L. (Helcocyrtomyia) goiana. This character can only be seen clearly under a 100x oil-immersion objective. The form of the spermathecae clearly distinguishes our material from Phlebotomus sp. 768 from French Guyana (Floch $\&$ Chassignet 1948), a species that Forattini (1973) synonymizes, without further comment, with $L$. souzacastroi.

\section{RESULTS}

Systematic list- Fifty-one species of Lutzomyia were identified among the 1645 specimens collected in light-traps, and one additional species (L. souzacastroi) was found only on tree trunks. Figures following the names of subgenera or species-groups refer to the relative abundance of the group in light-trap samples. Subgenus Lutzomyia (3.5\%): L. evangelistai, L. gomezi, L. marinkellei, L. falcata, L. flabellata. Subgenus Sciopemyia (6.0\%): L. servulolimai, L. sordellii. Species group Migonei (0.4\%): L. baculus, L. walkeri. Species group Verrucarum $(<0.1 \%)$ : L. serrana. Species group Saulensis (0.3\%): L. saulensis. Subgenus Pintomyia (0.6\%): L. christenseni. Subgenus Evandromyia (4.5\%): L. monstruosa, Lutzomyia sp. (Fig. 4). Subgenus Viannamyia (1.5\%): L. furcata, L. tuberculata. Subgenus Psathyromyia (2.0\%): L. abonnenci, L. campbelli, L. dendrophyla, L. lutziana, $L$. punctigeniculata, $L$. scaffi, L. shannoni, L. souzacastroi, L. cultellata. Species group Aragaoi (3.5\%): L. aragaoi, L. b. barrettoi, L. coutinhoi, L. runoides. Species group Dreisbachi (2.1\%): L. dreisbachi. Subgenus Trichopygomyia (1.2\%): L. wagleyi. Subgenus Nyssomyia (30.3\%): L. anduzei, $L$. antunesi, $L$. flaviscutellata, $L$. olmeca nociva, $L$. reducta, $L$. richardwardi, L. umbratilis, L. yuilli. Subgenus Trichophoromyia (30.4\%): L. octavioi, L. melloi, L. ubiquitalis. Subgenus Psychodopygus (13.3\%): L. amazonensis, L. ayrozai, L. carrerai, L. chagasi, L. claustrei, L. davisi, L. hirsuta, L. paraensis. Subgenus Micropygomyia (0.4\%): L. micropyga. Species goup Pilosa (0.3\%): L. pilosa.

Males of the species identified as L. gomezi have 30+ hairs in the coxite tuft, each as long as the width of the segment. This is more than has been described for L. gomezi, but fewer and longer than in the original description of the closely-related L. sherlocki by Martins et al. (1971). Despite fig. 42A of Young and Duncan (1994) and their considerations on the distribution of these two taxa, we continue for the moment to use the older name, while recognizing the possibility that our material may represent a geographical variant of $L$. sherlocki, or an undescribed species.

Analysis - The light-trap collection was dominated (Fig. 5) by four species that together contributed $54.6 \%$ of the sample. 21 species were moderately common $(0.5 \%-5.0 \%)$ while the remaining 26 species each contributed less than $0.5 \%$ of the total. Females outnumbered males by 12.1:1 for L. (Nyssomyia) spp, 2.3:1 for L. (Psychodopygus) spp., and 2.4:1 for the remaining species (except Trichophoromyia) combined. For $L$. (Trichophormyia) sp. males outnumbered females by $1.9: 1$.

Fig. 6 shows the cummulative totals of species and individuals with increasing numbers of subsamples. The traps equipped with rechargeable batteries captured significantly more phlebotomines than those with disposable cells (12.8 and 3.5 per trap-night, $\mathrm{P}<0.001$ ). Excluding the night on which only one type of trap was available, differences between the numbers of phlebotomines captured per night were not significant. In the comparison between the traps set at $0-50 \mathrm{~m}$ and $2000 \mathrm{~m}$ from the camp site, the mean number of specimens of $L$. (Psychodopygus) sp. captured per night was 16.9 and 4.9 , respectively $(\mathrm{P}<0.001)$, and 4.1 and 2.1 for L. servulolimai. These were also the only species among the few (41) phlebotomines taken on human bait. For total phlebotomines, including 20 damaged and unrecognizable specimens, the two sites were very similar (806 and 859).

Very few phlebotomines were found on the bases of tree trunks, and most of these were from the same tree: L. dendrophyla (57), L. flabellata (31), L. shannoni (29), L. souzacastroi (23), L. falcata (18), L. scaffi (13), L. marinkellei (8), L. christenseni (4), L. umbratilis (2), L. abonnenci (1). A single male of $L$. micropyga was found in a search of accumulated leaf litter in 20 acaulate palms (Astrocaryum sp.). One L. furcata and one $L$. tuberculata were found together in a hollow tree-trunk.

\section{DISCUSSION}

The 52 species of Lutzomyia identified in this geographically and chronologically restricted sample represent about $15 \%$ of all known species of the genus from continental South America, and over half the number of all phlebotomine species recorded after extensive surveys in the Brazilian state of Pará (Ryan 1986). Burgos and Hudson (1994) report only 37 species of phlebotomines from Suriname, including 32 species of Lutzomyia among 1556 individuals from CDC traps in rainforest in different parts of the country $(\alpha=5.7)$. 


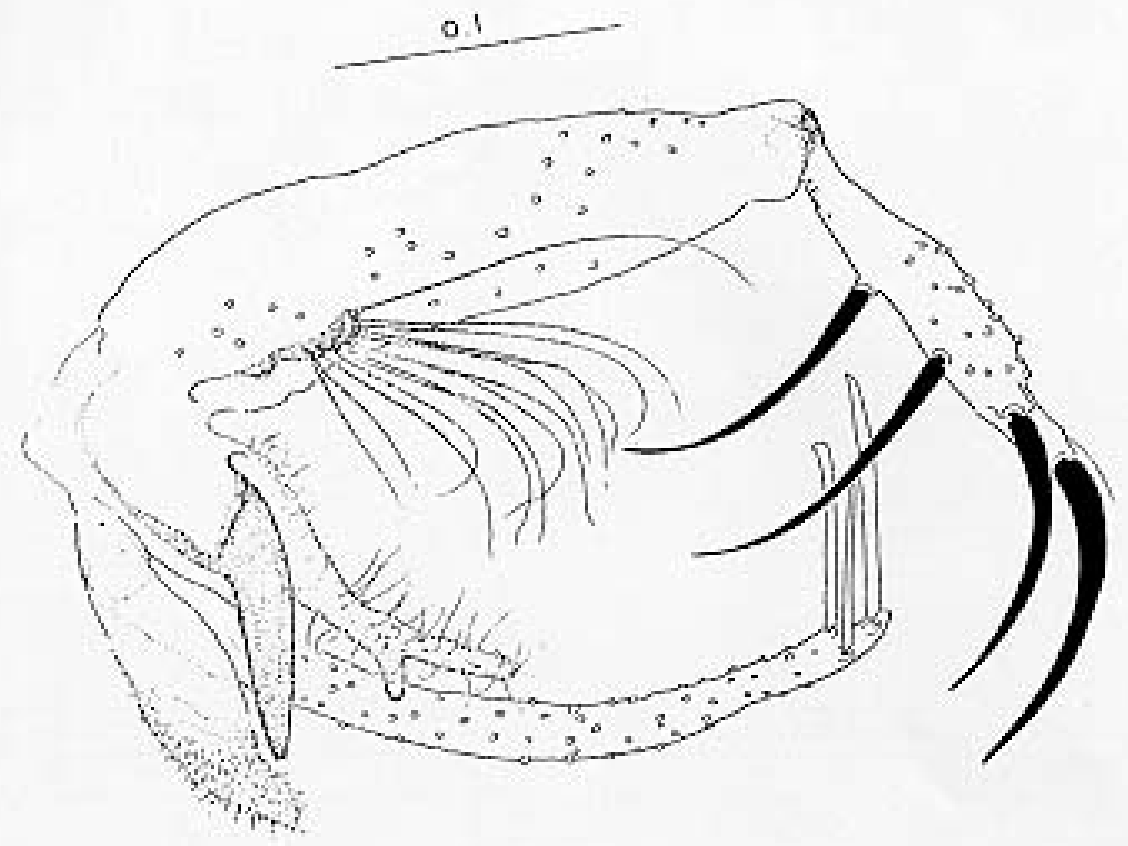

Fig 4: male terminalia of an undescribed species of the subgenus Evandromyia, the sixth most abundant species of Lutzomyia in lighttrap samples from Caiambé, also present elsewhere in the Brazilian Amazon Region.

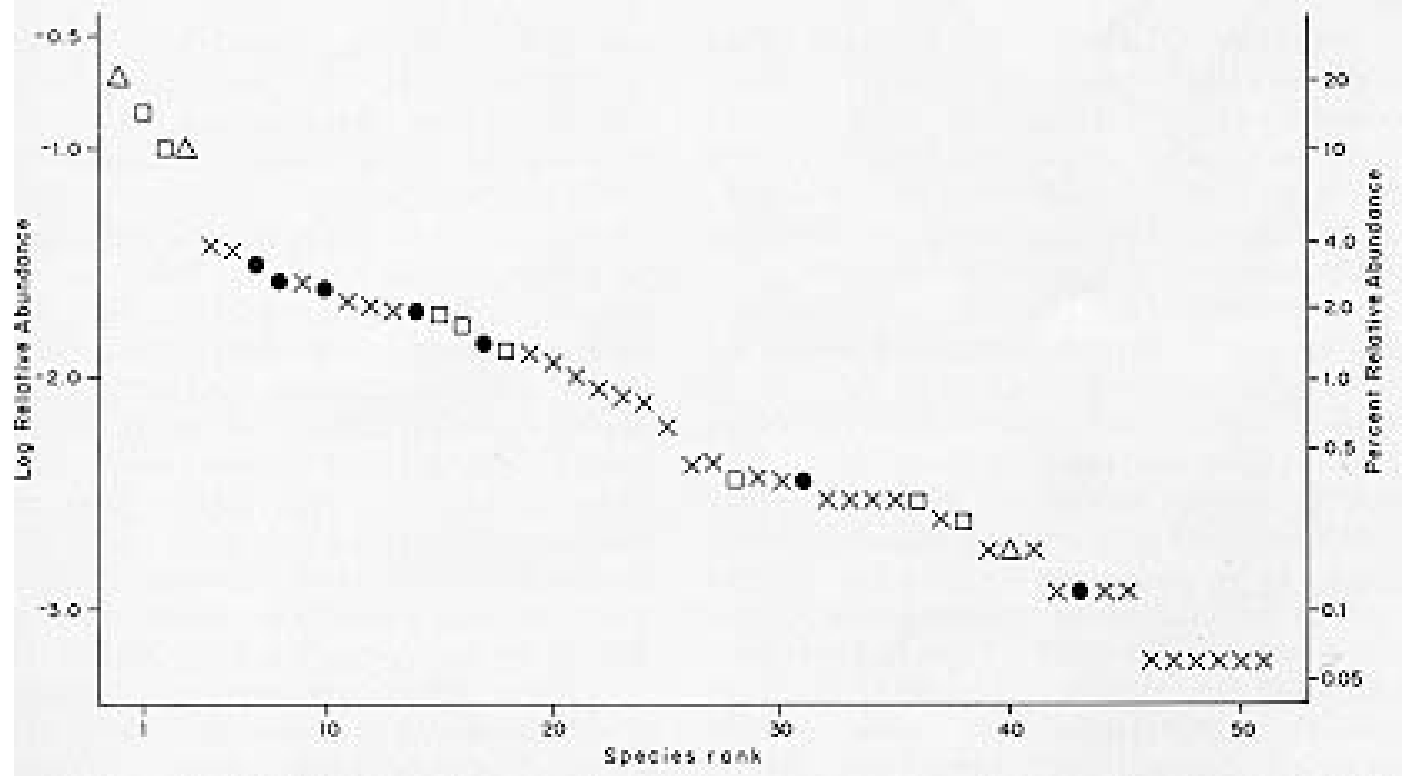

Fig. 5: log abundance on rank for Lutzomyia species in light-traps at 1m height. Brazil, State of Amazonas, Caiambé $03^{\circ} 40^{\prime} 42^{\prime \prime} \mathrm{S}, 64^{\circ}$ 21' 30" W, September 1991. Number of species $\mathrm{S}=51$, number of individuals $\mathrm{N}=1645$; diversity index $\alpha=10.0$. Species rank: $1 \mathrm{~L}$. ubiquitalis $(337=20.5 \%), 2$ L. yuilli $(238=14.5 \%), 3$ L. richardwardi $(163=9.9 \%), 4$ L. octavioi $(160=9.7 \%), 5$ L. servulolimai, 6 Lutzomyia sp. (Fig. 4), 7 L. ayrozai, 8 L. chagasi, 9 L. runoides, 10 L. paraensis, 11 L. sordellii, 12 L. dreisbachi, 13-14 L. gomezi, L. davisi, 15 L. umbratilis, 16 L. anduzei, 17 L. claustrei, 18 L. reducta, 19 L. furcata, 20 L. wagleyi, 21 L. amazonensis, 22 L. monstruosa, 23 L. evangelistai, 24 L. aragaoi, 25 L. christenseni, 26-27 L. micropyga, L. marinkellei, 28-31 L. flaviscutellata, L. punctigeniculata, L. shannoni, L. cultellata, 32-36 L. carrerai, L. pilosa, L. saulensis, L. dendrophyla, L. scaffi, 37-38 L. antunesi, L. baculus, 39-41 L. olmeca nociva, L. tuberculata, L. falcata, 42-45 L. melloi, L. walkeri, L. campbelli, L. hirsuta, 46-51 L. $b$. barrettoi, L. coutinhoi, L. abonnenci, L. flabellata, L. lutziana, L. serrana. Triangle $=L$. (Trichophoromyia) spp., Square $=L$. (Nyssomyia) spp., Circle $=$ L. (Psychodopygus) spp., $\mathrm{X}=$ other species. 


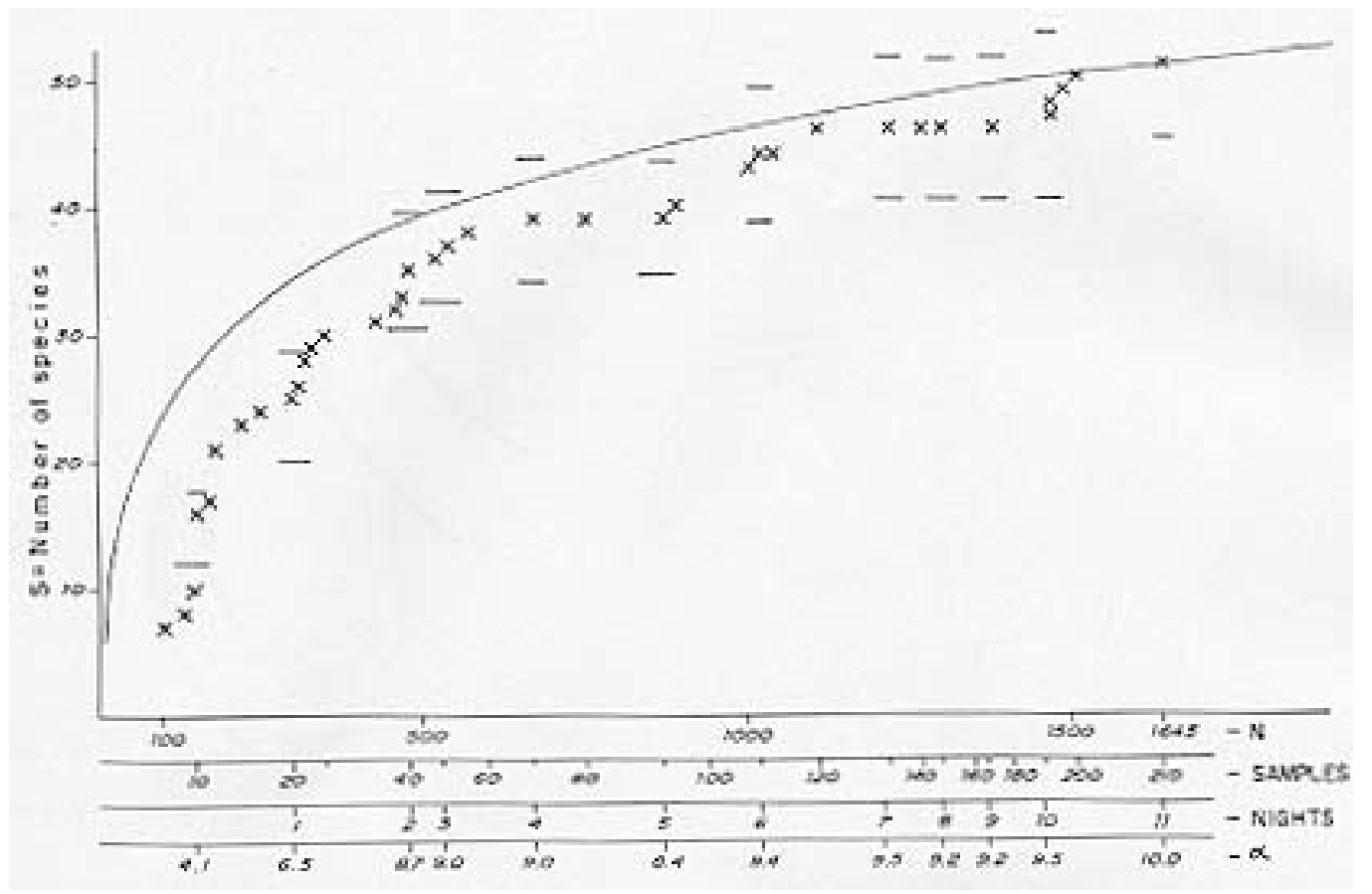

Fig. 6: collectors' curve for the sample described in Fig 5. X: observed numbers of species (S) and individuals (N) for intervals of 10 trap-nights; horizontal bars $=$ expected range of $\mathrm{S}$ for current value of $\mathrm{a} \pm 1$ standard deviation; solid line $=$ expected values for $\mathrm{a}=10.0$ and random distribution of individuals of each species among traps and nights; days are in chronological order.

The diversity index $\alpha$ in the log-series model is theoretically independent of sample size, although the effect on the variance makes estimates based on smaller samples less reliable (Wolda 1981). If Fig. 6 is representative, then $\alpha$ is probably not usually worth calculating for amazonian phlebotomines if $\mathrm{N}$ is much less than 1000 . The initial tendency of $\alpha$ to rise in Fig. 6 also suggests that the species were underdispersed among the subsamples. For example, of the 14 L. evangelistai, 13 were collected on the same night, when 5 were from the same trap; and it has been shown above that the samples collected near the camp-site may well have been biased in favour of anthropophilic species by the presence of the collectors. Assuming that sufficient further species remain, with a diversity index of $\alpha=10.0 \pm 1$ standard deviation, one would expect to detect about 68-84 species in a sample of 20,000 individuals from this area, after which additional species would be found at a rate of less than one per 2000 individuals.

The advantages of using insects as indicators of ecological diversity have been discussed by Brown (1991). Taxonomically, Phlebotominae are well-documented and now relatively stable, and large numbers can conveniently be transported and stored in small volumes of alcohol. In addition to being directly dependent on the vertebrate fauna, they are also hosts of vertebrate kinetoplastid parasites that are themselves of phylogenetic and ecological interest (Molyneux et al. 1985). Phlebotomines are widely collected because of their public health importance, but much ecological information is often lost in surveys, through pooling hetereogeneous samples or failure to record relative abundance or sample size. Simply listing the species found in a particular area is not particularly informative, because the absence of a species from a sample is impossible to evaluate (Bullock 1971) and the limits of local faunas therefore cannot be determined from data on presence or absence alone (Martins \& Morales Farias 1972). Southwood (1978) has recommended presenting diversity data as graphs of log abundance on rank (Fig. 5). By listing, in addition, the species corresponding to each rank, the number of individuals of each species can be recovered for further analyses including studies of beta-diversity (Grassle \& Smith 1976, Wolda 1983).

\section{ACKNOWLEDGEMENTS}

To Petróleo Brasileiro SA and Geophysical Survey Team ES-238 for logistic support in the field. To Dr Alda Falcão (FIOCRUZ) for her efforts on our behalf to locate Damasceno and Causey's second specimen of Flebotomus souzacastroi (paratype, missing, believed lost). All figures are by Artêmio Coelho da Silva (INPA). 


\section{REFERENCES}

Barrett TV, Freitas RA, Hurtado Guerrero JC 1993. Ensaio de termonebulização na floresta em área de prospecção de petróleo: efeitos sobre flebotomíneos. Anais da 45ํ. Reunião Anual da Sociedade Brasileira para o Progresso da Ciência 1: 320 (Resumo 23-A.9).

Brown Jr KS 1991. Conservation of Neotropical Environments: Insects as Indicators, p. 349-404. In NM Collins, JA Thomas (eds). The Conservation of Insects and their Habitats. (Royal Entomological Society Symposium XV) London, Academic Press.

Bullock JA 1971. The investigation of samples containing many species. II. Sample comparison. Biol J Linnean Soc 3: 23-56.

Burgos AM, Hudson JE 1994. Annotated list of the Phlebotominae (Diptera) of Suriname. Mem Inst Oswaldo Cruz 89: 171-178.

Damasceno RG, Causey OR 1944. Estudo sôbre Flebotomus no Vale Amazônico. Parte I. Descrição de F. marajoensis, F. pilosus, F. souzacastroi e F. christophersoni (Diptera: Psychodidae). Mem Inst Oswaldo Cruz 41: 339-350. pls 1-5.

Dias ES, Falcão AL, Silva JE, Martins AV 1991. Taxonomic studies of the subgenus Helcocyrtomyia. I. Series Oswaldoi (Diptera, Psychodidae, Phlebotominae). Mem Inst Oswaldo Cruz 86: 323-340.

Floch H, Chassignet R 1948. Phlébotomes de la Guyane Française (XXIV) Description de deux femelles nouvelles. Inst Pasteur Guyane, Publ No. 170, 6pp.

Forattini OP 1973. Entomologia Médica IV. Psychodidae. Leishmanioses. Bartonelose. São Paulo, Edgard Blucher, 658pp.

Grassle JF, Smith W 1976. A similarity measure sensitive to the contribution of rare species and its use in investigation in Marine Benthic Communities.
Oecologia 25: 13-22.

Martins AV, Morales Farias EN 1972. Sobre a distribuição geográfica dosflebotomíneos americanos (Diptera, Psychodidae, Phlebotominae). Rev Bras Biol 32: 361-371.

Martins AV, Silva JE, Falcão AL 1971. Lutzomyia sherlocki sp.n., do Estado de Mato Grosso, Brasil (Diptera, Psychodidae, Phlebotominae) Rev Brasil Biol 31: 415-418.

Molyneux DH, Ryan L, Lainson R, Shaw JJ 1985. The Leishmania - sand fly interface, p. 311-324. In Leishmania, Taxonomie et Phylogenese. Aplications ecoepidemiologiques. Coll Int CNRS/INSERM, 1984 IMEEE, Montpellier.

Ryan L 1986. Flebotomos do Estado do Pará, Brasil. Belém, Instituto Evandro Chagas (Documento Técnico No. 1) 154 pp.

Southwood TRE 1978. Ecological methods with particular reference to the study of insect populations. 2nd ed. London, Chapman \& Hall, 524pp.

Taylor LR, Kempton RA, Woiwood IP 1976. Diversity Statistics and the Log-series Model. J Animal Ecology 45: 255-272.

Theodor O 1965. On the classification of American Phlebotominae. J Med Ent 2: 171-197.

Wolda H 1981. Similarity indices, sample size and diversity. Oecologia 50: 296-302.

Wolda H 1983. Diversity, diversity indices and tropical cockroaches. Oecologia 58: 290-298.

Young DG, Duncan MA 1994. Guide to the identification and Geographic Distribution of Lutzomyia Sand Flies in Mexico, The West Indies, Central America and South America (Diptera: Psychodidae). Memoirs of the American Entomological Institute No. 54. Gainesville, Associated Publishers, $881 \mathrm{pp}$. 
Collection of Lutzomyia in Amazonas - Toby V Barrett et al. 